\title{
Nosological profile and prevalence of common mental disorders of patients seen at the Family Health Program (FHP) units in Petrópolis, Rio de Janeiro Perfil nosológïco e prevalência de transtomos mentais comuns em pacientes atendidos em unidades do Programa de Saúde da Família (PSF) em Petrópolis, Rio de Janeiro
}

\author{
Sandra Fortes, ${ }^{1}$ Luiz Augusto Brites Villano, ${ }^{1}$ Claudia S Lopes ${ }^{2}$
}

\begin{abstract}
Objectives: This study aims to detect the prevalence of common mental disorders among patients seen by doctors at family health program units in Petrópolis-RJ, and to establish their nosological profile. Method: The population of the study included all 18 to 65-yearold patient who attended any family health program units included in the study during a 30-day period, between August and December 2002 ( $n$ = 714). The prevalence of common mental disorders was assessed using the General Health Questionnaire, 12 item version. In order to establish the nosological profile, the Composite International Diagnostic Interview was administered to all common mental disorders positive patients who accepted to return $(n=215)$. Results: At the cut-off point of 2/3 the common mental disorders prevalence was $56 \%$ and for $4 / 5$, it was 33\%. The most frequent nosological categories found among common mental disorders positive patients were depression and anxiety categories along with posttraumatic stress disorder, somatoform pain disorder and dissociative disorders. There was a high frequency of comorbidity, especially between anxiety, depression, somatoform and dissociative disorders. Conclusions: The common mental disorders prevalence and the nosological profile found in FHP were similar to those of other primary care studies in Brazil, but some disorders (posttraumatic stress disorder, somatoform pain disorder and dissociative disorders) that had not been previously studied in this context were also very frequent. The high common mental disorders prevalence found reinforces the urgent need for systematic inclusion of this level of care in mental health assistance planning.
\end{abstract}

Descriptors: Mental disorders; Epidemiology; Prevalence; Primary health care; Family health

\section{Resumo}

Objetivos: Conhecer a prevalência de transtornos mentais comuns na clientela atendida no Programa de Saúde da Família (PSF) em Petrópolis-RJ e seu perfil nosológico. Método: Foram estudados todos os pacientes entre 18 e 65 anos atendidos no período de 30 dias, entre agosto e dezembro de $2002(n=714)$. A prevalência de transtornos mentais comuns foi avaliada por meio do General Health Questionnaire 12 itens. Aos pacientes considerados positivos para transtornos mentais comuns foi aplicado o Composite International Diagnostic Interview para caracterização nosológica $(n=215)$. Resultados: Detectou-se prevalência de $56 \%$ de transtornos mentais comuns para o ponto de corte 2/3 e de 33\% para 4/5. As categorias nosológicas mais comumente encontradas entre os pacientes com transtornos mentais comuns positivos foram depressão e ansiedade, junto com transtorno de estresse pós-traumático, transtorno de dor somatoforme e transtornos dissociativos. Houve alta freqüência de comorbidade, especialmente entre transtornos ansiosos, depressivos, somatoformes e dissociativos. Conclusões: A prevalência de transtornos mentais comuns e o perfil nosológico encontrados foram equivalentes àqueles de outros estudos em Atenção Primária no Brasil, porém destacaram-se transtornos não pesquisados anteriormente neste campo (transtorno de estresse pós-traumático, transtorno de dor somatoforme e transtornos dissociativos). A alta prevalência de transtornos mentais comuns reforça a necessidade urgente de inclusão sistemática desse nível de cuidado no planejamento da assistência em saúde mental.

Descritores: Transtornos mentais; Epidemiologia; Prevalência; Atenção primária à saúde; Saúde da família

\footnotetext{
1 Faculdade de Ciências Médicas, Universidade do Estado do Rio de Janeiro (UERJ), Rio de Janeiro (RJ), Brazil

2 Instituto de Medicina Social, Universidade do Estado do Rio de Janeiro (UERJ), Rio de Janeiro (RJ), Brazil
}

This study was carried out as part of the first author's PhD dissertation in Collective Health at the Instituto de Medicina Social, Universidade do Estado do Rio de Janeiro (UERJ), Rio de Janeiro (RJ), Brazil

Financing: Grant for Public Health PhD Thesis from the Pan-American Health Organization

Conflict of interests: None

Submitted: April 29, 2007

Accepted: September 11, 2007
Correspondence Sandra Fortes

R. Barão de Mesquita, 36/401 - Maracanã

20540-010 Rio de Janeiro, RJ, Brazil

E-mail: sandrafortes@gmail.com 


\section{Introduction}

Mental health problems presented by patients attending general health units have been object of different studies since the 80's. The findings of the Epidemiological Catchment Area Study (ECA) - a multicenter community study performed in the U.S.A - demonstrated that $40-60 \%$ of the mental health demands were being seen by general practitioners in primary care units., ${ }^{1,2}$ The multicenter study sponsored by the WHO in the beginning of the 90's - "Psychological Problems in General Health Care" (PPGHC/WHO) ratified the high prevalence of mental health disorders at this level of care, with a mean of $23 \%$ in 15 countries, including Brazil. ${ }^{3-5}$ It was considered a specific demand, with different characteristics from those patients seen at specialized mental health clinics, emphasizing the fact that a large number of patients with emotional suffering tend to seek treatment with general practitioners.

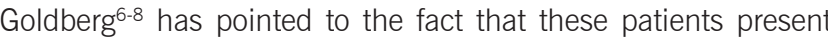
acute anxiety and depression disorders, with less serious symptoms, associated with stressful life events, which often remit spontaneously, and a predominance of somatic symptoms on their presentation, in counterpoint to psychological symptoms. These disorders have been called common mental disorders (CMD), and have been studied in community settings and in primary care units in various countries. The worldwide research on CMD has ratified its prevalence of $18 \%$ and $27 \%^{9-11}$ in different communities. In Brazilian community studies, these percentages range from $19 \%$ to $40 \% .{ }^{12-16}$ The largest worldwide ${ }^{3}$ study carried out in general health units was the PPGHC/WHO, which has found prevalence ranging from $12.2 \%$ in Ankara (Turkey) to $51 \%$ in Chile. There have been other outstanding studies that have demonstrated prevalence of $23.4 \%$ to $58.8 \% .{ }^{17}$

20 In Brazil, there are very few studies on CMD prevalence among patients of general care units. One of them ${ }^{4}$ was carried out in a general outpatient service at a university hospital, and it was part of the PPGHC/WHO. This study included not only CMD but also the prevalence of some of the most important categories from the ICD-10, having found a prevalence of $38 \%$ of mental disorders with at least one ICD-10 diagnosis. Three other studies were conducted in Basic Health Units (UBS - Primary Care Units) back in the eighties. ${ }^{21-23}$ Only one ${ }^{21}$ of them has included the prevalence of specific nosological categories. The others have aimed at detecting the prevalence of CMD in primary care, which was around $50 \%$ of all patients attending these units.

Some of the international studies on CMD held in primary care units have also aimed at establishing the nosological profile of its patients. $3,4,24$ There is a predominance of depression and anxiety disorders, followed by alcohol-related and somatoform disorders. The comorbidity of these disorders is also quite common. ${ }^{3,7,24}$ In the PPGHC/WHO study, between $2.3 \%$ and $33.3 \%$ of the patients have presented more than one diagnosis, with emphasis on those between the subtypes of depressive disorders and the different categories of disorders associated with somatization (somatoform and dissociative disorders). In the WHO multicenter study on somatoform disorders, around $24 \%$ of the patients studied fulfilled the criteria for more than one of these disorders. ${ }^{25,26}$

Primary care assistance underwent several changes in Brazil during the last decade due to the organization of the new Family Health Program (FHP), which aims at being able to solve $80 \%$ of all health problems, including mental health ones. Unfortunately, most of the professionals working in the Family Health Teams are not adequately trained to deal with patients presenting this type of problems, which must be better understood on their prevalence, nosological profile, determinants and symptomatology in this level of the health system. This knowledge is essential to organize specific primary care therapeutic interventions and adequate mental health training of the teams, so that morbidity, costs, and the patients' disability level can be reduced. No other study has been carried out before to determine the prevalence of CMD among patients seen by the teams from the FHP.

This study is part of the "Petropolis Study", from the Research Line on "Mental Health and Primary Care" (CNPq). The objective of this study is to determine the prevalence of CMD among the patients seen at the Family Health Program (FHP) in the Municipality of Petrópolis, State of Rio de Janeiro, and establish, with no definition of any specific prevalence, the nosological profile of these patients according to the CID-10, ${ }^{27}$ also examining the occurrence of comorbidity.

\section{Method}

\section{Research design and population}

The study was conducted as a survey in five (5) urban units of the Family Health Program (FHP) in the Municipality of Petrópolis. These units were selected because they were receiving undergraduate nurse and medical students for training. Petrópolis is located in the mountainous region of the State of Rio de Janeiro, with a population of 300,000 inhabitants in rural and industrialized urban areas. At the time of the survey, there were 25 teams in the Family Health Program, which, according to the guidelines of the Ministry of Health, should serve between 600 and 1,000 families each, depending on the specific characteristics of each area. The five areas present patients with similar profiles as far as their urban socioeconomic characteristics are concerned. The reference population for the sample population consisted of those patients seen at these five units from August to December 2001, totaling 4,928 patients. Interviews were initially held with all patients from 18 to 65 years of age, seen by the family doctor, for a period of 30 days in each unit, between August and December 2002. Those patients younger than 18 years or older than 65 years of age, and those with abnormal cognitive functioning were excluded from the study.

\section{Measures}

All patients answered a questionnaire to determine their socioeconomic and demographic profile.

The prevalence of common mental disorders was assessed using the General Health Questionnaire comprising 12 items (GHQ-12), which was administered to all patients. This questionnaire is a well established standardized screening tool ${ }^{28}$ and was validated in its Brazilian version ${ }^{29}$ having the Clinical Interview Schedule as the gold standard. The cut-off point used to characterize the patients as having CMD was 3 positive answers out of 12 (referred to as GHQ3 from now on). In order to determine the more intensive and severe disorders, a cut-off point of 4/5 (GHQ5) was considered, as recommended by the PPGHC/WHO study. The Brazilian version of GHQ-12, at the cut-off point of 2/3, showed sensitivity of $91 \%$ and specificity of $71 \%$, and, at the cut-off point of $4 / 5$, for a population with no more than four years of schooling, sensitivity of $76 \%$ and specificity of $82 \% .5,30$ Even though it is a highly sensitive tool, some patients were not identified as specific cases, mainly those under psychiatric treatment because, during the period in which the questionnaires were answered ( 15 days prior to the interview), many of them may have been non-symptomatic. Following the orientation of the GHQ Manual, ${ }^{31}$ two extra questions were added in order to determine false negatives:

1) "Have you used any medication in the last two (2) weeks?" (Positive in cases of use of psychotropic).

2) "Have you considered yourself as a nervous person/suffering from nervous disorders sometime in the last two (2) weeks?"

All questionnaires were read to the patients by the interviewers (who were students from the Medical and Psychology Colleges 
locate in Petrópolis). This methodological adaptation has often been used in Brazilian public research projects ${ }^{4,5,27}$ due to the low level of literacy of the population.

All the GHQ positive (2/3 cut-off point) patients, as well as those $\mathrm{GHQ}$ patients who were suspected of being false negatives by the above mentioned criteria, were invited to a second interview in order to establish their nosological profile through a structured interview, using the Composite International Diagnostic Interview (CIDI). This structured interview was devised by Robbins et al. with the purpose of defining the mental disorders present, according not only to the CID-10 but also to the DSM-IV. ${ }^{32}$ We used the Brazilian version of the CIDI 2:1, whose validation shows sensitivity ranging from $13.2 \%$ for substance related disorders to $67.3 \%$ for depressive disorders and specificity ranging from $79.6 \%$ for depressive disorders to $100 \%$ for eating disorders. ${ }^{33}$ This sample was deliberately biased since one of the aims was to identify the highest possible number of false negative GHQ so that a detailed nosological profile of those patients with CMD could be established. Therefore, the study did not intend to estimate the lifetime prevalence of specific psychiatric diagnosis in the whole population of patients who visited the FHP.

The SPSS 8 was used for data analysis.

\section{Ethical considerations}

This research was submitted to the consideration of the Ethics Committee of the Social Medicine Institute, UERJ (Comitê de Ética do Instituto de Medicina Social/UERJ) and was regarded as adequate to be applied to a human population.

\section{Results}

Interviews were held with 714 patients (93\% of the total seen by the doctors during the period), with the following socioeconomic profile: predominantly female (74.1\%), the majority of them married $(60.8 \%)$. As to race: $52.1 \%$ considered themselves as whites. The most common religious group was Catholic (57.6\%). Educational level was very low, considering that $8.7 \%$ were illiterate, $45.3 \%$ had studied up to the 4 th Grade of Elementary School and only $22.9 \%$ had finished it (8th Grade). The age distribution in three levels revealed a slight predominance of patients in the 50 to 65 age bracket (39.5\% of the total number). It is a low income population, $88 \%$ of which had a per capita monthly income of up to one minimum wage (U\$ 80). The sample consisted of $31.8 \%$ of patients who sought emergency care, $36.6 \%$ came for individual return visits, and $25.1 \%$ were group patients. The sociodemographic data of the sample is shown on Table 1.

The prevalence of CMD (at the GHQ-12 cut-off point of 2/3) was $56 \%(95 \% \mathrm{Cl}, 52.36-59.04, \mathrm{n}=400)$. Among the $314 \mathrm{GHQ}$ negative patients, 69 (9.6\% of the total) were identified as false negatives. For the $4 / 5$ cut-off point, the prevalence of positive patients was 33\% (95\% $\mathrm{Cl}, 29.55-36.45, \mathrm{n}=251$ ). If we adjust by the GHQ specificity and sensitivity for the 2/3 cut-off point, we'll find an adjusted prevalence of $64 \%$ of CMD, and for the cut-off point of $4 / 5$, it will be of $37 \%$.

There was a return of 215 patients for the CIDI (around $45 \%$ of the total positives). They are similar to the total amount of patients that were positive for CMD for GHQ mean values and all socioeconomic variables (sex, income, educational level, and marital status), except for age, since they were significantly younger $(p=0.003)$. There was a loss of five (5) patients $(2 \%)$ that could not complete the interview due to cognitive deficits. Of these 215 patients, 55 (25.6\%) were considered as negatives in the CIDI evaluation. Among the 155 patients with a CIDI diagnosis, 34 (16\% of 215 patients) presented only one diagnosis during lifetime. The others ( $56 \%$ of the total) presented more than one diagnosis, reaching a maximum of nine (9) diagnoses. The mean of the sample was 2.2 diagnoses per patient.
Table 1 - Sociodemographic and economic characteristics of the sample $(n=714)$

\begin{tabular}{|c|c|c|}
\hline Variables & n & $\%$ \\
\hline \multicolumn{3}{|l|}{ Sex } \\
\hline Female & 529 & 74.1 \\
\hline Male & 185 & 25.9 \\
\hline \multicolumn{3}{|l|}{ Age group } \\
\hline 18 to 33 years & 163 & 23 \\
\hline 34 to 49 years & 266 & 37.5 \\
\hline 50 to 65 years & 380 & 39.5 \\
\hline \multicolumn{3}{|l|}{ Marital status } \\
\hline Married/Living together & 434 & 60.8 \\
\hline Separated/Divorced & 69 & 9.7 \\
\hline Widow/Widower & 81 & 11.3 \\
\hline Single & 129 & 18.1 \\
\hline \multicolumn{3}{|l|}{ Monthly income (USD) } \\
\hline 0 to 60 & 244 & 35 \\
\hline 61 to 80 & 276 & 39.5 \\
\hline 81 to 120 & 111 & 15.9 \\
\hline 121 to 160 & 36 & 5.2 \\
\hline More than 161 & 31 & 4.4 \\
\hline \multicolumn{3}{|l|}{ Ethnicity } \\
\hline White & 372 & 52.1 \\
\hline Black & 149 & 20.9 \\
\hline Mulatto & 176 & 24.6 \\
\hline Other & 17 & 2.4 \\
\hline \multicolumn{3}{|l|}{ Religion } \\
\hline Catholic & 411 & 57.6 \\
\hline Protestant & 246 & 34.6 \\
\hline Other & 57 & 7.8 \\
\hline \multicolumn{3}{|l|}{ Education level } \\
\hline Illiterate & 62 & 8.7 \\
\hline$<4$ years of study & 323 & 45.3 \\
\hline 5 to 7 years of study & 164 & 23 \\
\hline Basic education & 65 & 9.1 \\
\hline$>8$ years of study & 99 & 13.8 \\
\hline \multicolumn{3}{|l|}{ Type of visit } \\
\hline Urgent consultation & 227 & 31.8 \\
\hline First consultation (booked) & 40 & 5.6 \\
\hline Individual follow-up & 261 & 36.6 \\
\hline Group follow-up & 179 & 25.1 \\
\hline
\end{tabular}

The frequency of the main syndromes found in patients with common mental disorders (being either positive or false negatives at the GHQ) that responded the CIDI can be seen in Figure 1 . Anxiety $(n=86,40 \%)$ and depressive syndromes ( $n=97,45 \%$ ) are outstanding. The high frequency of somatization ( $n=47,22 \%$ of somatoform disorders and $n=44,20 \%$ of dissociative disorders) is also important, as are the disorders related to alcohol abuse (10.9\%).

Table 2 shows the percentages of the disorders elicited among patients with common mental disorders, not only current but also lifetime problems. The most frequent, in a decreasing order, were: posttraumatic stress disorder, somatoform pain disorder, dissociative motor disorders, moderate and severe depressive episodes, dysthymia, agoraphobia, generalized anxiety disorder, and dissociative anesthesia.

There was comorbidity among depressive and anxiety syndromes in 57 patients (26.5\% of the total CIDI patients), and those syndromes were also related to chronic somatization. The majority of the patients with somatoform disorders (77\%) presented anxiety or depressive disorders during their lifetime. One third of those with dissociative disorders presented more than one dissociative disorder and $70 \%$ had comorbidity with anxiety and/or depressive disorders. The association between somatoform and dissociative disorders is also high, reaching $30 \%$ of those patients with dissociative disorders.

\section{Discussion}

The crude prevalence of CMD in the FHP Units in Petrópolis was $56 \%$, which is similar to the ones found by previous 


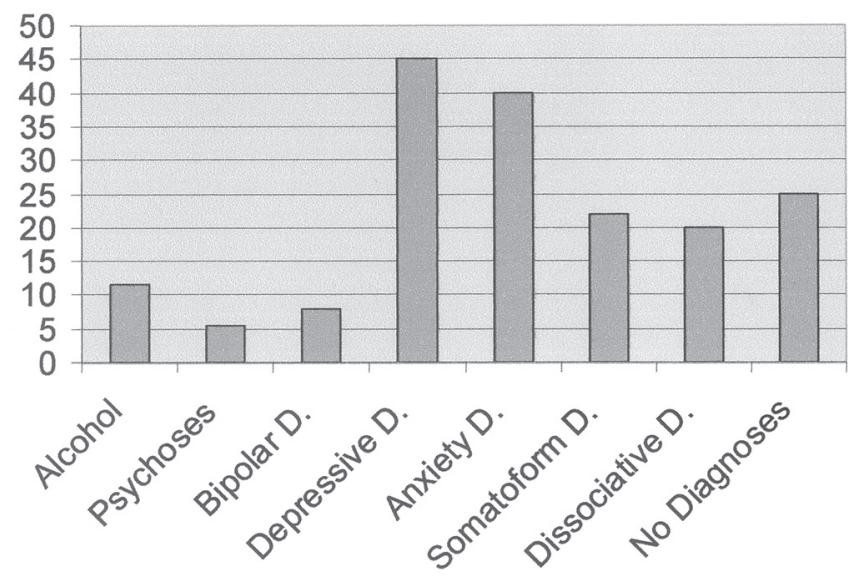

Figure 1 - Percentage of lifetime mental disorders by syndrome group in the positive CMD patient sample $(n=215)$

studies carried out in Brazil during the 80's by Busnello, ${ }^{21}$ Mari, ${ }^{22}$ lacopponi, ${ }^{23}$ and by Villano ${ }^{5}$ in 1998 . When the $4 / 5$ cut-off point is used, we find an adjusted prevalence of $37 \%$ of the patients with mental disorders of severe intensity (according to the criteria applied by the PPGHC/WHO), a percentage that is very similar to the $38 \%$ prevalence of psychiatric disorders found by Villano et al. in Rio de Janeiro in general outpatient units. ${ }^{5}$

There is a subgroup of the GHQ positive patients (25\%) that are presumed to have CMD but who went undetected in the CIDI diagnosis. This difference, besides the psychometric characteristics of the screening instrument, may be explained by the inadequacy of the classifications presently used in psychiatry for patients seen in primary care units. ${ }^{7,34,35}$ The main reason for this inadequacy originates from the existing classification model, categorical by definition and organized according to the data from patients seen by specialized units. In primary care, the discontinuity among the different psychiatric disorders (anxiety and depression, for example), and between these and normality is even less well defined. The symptoms distribute themselves in a dimensional way and suffer modifications over time, including spontaneous remission, 7,24,35,36 which makes the categorical classifications inappropriate.

Although the prevalence of specific psychiatric diagnosis in the general population that seeks primary care at the FHP units was not assessed, the profiles of the most frequent psychiatric disorders found in patients with CMD can show the nosological hierarchy in that type of setting, giving important clues to health planning and directing further research. In the following paragraphs we will analyze these profiles, comparing them with the results found in prevalence studies of psychiatry disorders in primary care settings, both in Brazilian and international studies. When we are dealing with the nosological distribution, it must be kept in mind that the proportions found in this study do not mean prevalence rates, as only patients with CMD were interviewed, and for this reason the numbers are not shown.

Depression was the most frequent syndrome among patients with CMD. The different subtypes found are typical of this type of demand. It is surprising that among them a high frequency of severe cases (severe episodes and recurrent disorders) was found. Anxiety disorders were also very common. Alcohol abuse and dependence also appear as an important diagnosis among these patients, as well as in the PPGHC/WHO. ${ }^{4}$
Table 2 - Current and lifetime mental disorders (by CIDI) in a positive CMD patient sample $(n=215)$

\begin{tabular}{|c|c|c|}
\hline ICD-10 (CIDI 2:1) & $\begin{array}{l}\text { Percentage } \\
\text { diagnosis } \\
\text { lifetime }\end{array}$ & $\begin{array}{c}\text { Percentage } \\
\text { diagnosis } \\
\text { current }\end{array}$ \\
\hline F10.1 Harmful use of alcohol & 5.6 & 0.5 \\
\hline F10.2 Alcohol dependence syndrome & 6 & 0.5 \\
\hline F20 Schizophrenia & 2.8 & 2 \\
\hline F23 Acute and transient psychotic dis. & 0.9 & 0.5 \\
\hline F30.1 Mania without psychotic symptoms & 4.2 & 2 \\
\hline F32.0 Mild dep. Episode & 5.6 & 2 \\
\hline F32.1 Moderate dep. Episode & 13.5 & 6.5 \\
\hline $\begin{array}{l}\text { F32.2 Severe dep. Epis. (w/o psych. } \\
\text { symp.) }\end{array}$ & 12.6 & 5 \\
\hline F33.0 Recurrent depressive dis. (mild) & 1.9 & 1.9 \\
\hline $\begin{array}{l}\text { F33.2 Rec. dep. dis. (sev.) w/o psych. } \\
\text { symp. }\end{array}$ & 8.8 & 7.5 \\
\hline F31 Bipolar disorder & 3.7 & 2.8 \\
\hline F34.1 Dysthymia & 12.6 & 5.6 \\
\hline F25 Schizoaffective dis. & 1.8 & 1.8 \\
\hline F40.0 Agoraphobia & 12.1 & 9.8 \\
\hline F40.00 Agoraphobia w/o panic & 11.4 & 8.8 \\
\hline F41.1 Generalized anxiety dis. & 12.6 & 11.6 \\
\hline F45.0 Somatization dis. & 0.5 & 0.5 \\
\hline F45.2 Hypochondriac dis. & 2.8 & 2.8 \\
\hline F45.4 Persistent somatoform pain dis. & 19.1 & 13 \\
\hline F44.0 Dissociative amnesia & 1.9 & 0.9 \\
\hline F44.4 Dissociative motor dis. & 14.4 & 8.4 \\
\hline F44.5 Dissociative convulsions & 0.9 & 0.9 \\
\hline $\begin{array}{l}\text { F44.6 Dissociative anesthesia/sensory } \\
\text { loss }\end{array}$ & 12.6 & 6 \\
\hline F42 Obsessive-compulsive dis. & 1.4 & 0.5 \\
\hline F43.1 Posttraumatic stress dis. & 26 & 7.5 \\
\hline
\end{tabular}

Dis. $=$ disorder; Dep $=$ depressive $;$ Rec $=$ recurrent $;$ Epis $=$ episode $:$ W/o $=$ without; Psych. $=$ psychotic; Symp. $=$ symptoms; Sev. $=$ severe

The results are compatible with those found by Villano in the multicenter $\mathrm{WHO}^{4,5}$ study (Psychological Problems in General Health Care - PPGHC/1995) in the city of Rio de Janeiro. In that study, the high prevalence of anxiety disorders in Brazil was different from the predominance of depressive disorders found in most other centers. ${ }^{4}$ The importance of anxiety disorders among the pathologies presented by these patients is confirmed in the present study. The use of the CIDI 2:1 made it possible to find a high frequency of posttraumatic stress disorders (PTSD) not detected by previous studies due to limitations of the research instruments that were then available. It is possible that the high prevalence of anxiety disorders found by Villano may have included PTSD, which was not considered at the time. This was the main subtype of anxiety lifetime disorder, even if not present at the moment of evaluation, when the predominant disorders were generalized anxiety and phobias. As in Villano study, ${ }^{4}$ no cases of panic disorders were found here.

An interesting aspect of the nosological profile that was found is the greater accuracy of the data concerning those disorders related to somatization phenomena. The use of the CIDI 2:1, which applies more specific and restrictive criteria, demonstrated the inadequacy of "somatization disorder" as the main category to classify this phenomenon. While the somatization phenomenon ${ }^{35-38}$ is, in itself, quite common, somatization disorder is less frequent $10.5 \%$ of the patients evaluated), as has been verified by other studies. ${ }^{24,39}$ It seems that, as a category, this disorder is not related to the alterations presented by these patients, with unspecific somatic complaints and, while being the main diagnosis category of this group, it is quite rare in comparison to the others. Somatoform pain disorder stands out as a more frequent category in this population. This category had already shown itself to be the most frequent (present in a mean of $15 \%$ of the patients) among subtypes of the somatoform disorders in the WHO Somatoform Disorders Multicenter 
Study. ${ }^{25}$ It is necessary to emphasize the importance of pain as a reason to seek treatment. It has been recognized as the main complaint of patients in general health units by many research projects, including the PPGHC/WHO. ${ }^{3,25,40}$ Pain stands out as an important symptom related to somatization due to its subjective nature and to the fact that it is often associated with mental disorders in general. This inadequate categorizing of somatoform disorders has also been detected in other worldwide studies on somatization and has been questioned by specialists on the area. ${ }^{36-39}$ Another interesting finding among those diagnostic categories involved in the somatization phenomenon are the dissociative disorders (found in $20 \%$ of the patients), motor and anesthetic, which showed them to be quite frequent in our population and which have been very seldom studied in other populations. ${ }^{3}$ Once again, it has been confirmed how frequently we find diagnosis comorbidities among distinct syndromes that present somatization phenomenon (somatoform and dissociative) and depressive and anxiety disorders.

The high frequency of comorbidity confirms the need of reviewing the existing psychiatric classifications concerning the nosological profiles of patients of the basic health units. As far as this group of patients is concerned, mental disorders seem to place themselves more in a continuum of symptoms than in distinct categories - even if these categories represent the basis of the present classifications. The inadequacy of the categories presently used for primary care patients is consensual, and the WHO has devised a specific classification for the primary care units, the CID-10-AP. ${ }^{34}$

Our study has several limitations. The most important one is that we worked with common mental disorders, as defined by the $\mathrm{GHQ}$, and that it was not possible to determine the real prevalence of each of the main categories diagnosed by the CIDI, as we did not consider their frequency in the GHQ negative patients. We had a return of $45 \%$ of the patients invited for the CIDI, a result similar to the Latin American centers in the PPGHC/WHO study. ${ }^{3}$ We probably had a detection bias in the patients' return for the CIDI, which is an instrument that requires a long time of application and great availability on the part of the patient demanding a special motivation from them, which may bring an overrepresentation of the most severe cases. On the other hand, since our secondary objective was to establish the nosological profile of these patients, we believe we attained our objective by revealing the importance of mental disorders such as the PTSD and somatoform pain disorder, which had not been previously studied.

Our attention has been drawn to the high number of posttraumatic stress disorders found by this study. We do not find it possible to make general inferences based on this regarding other parts of the country, because it could reflect data that is specifically related to the Municipality of Petrópolis. Being located in a mountainous region, Petrópolis often suffers with heavy summer rains and consequent landslides - the very communities in which this research was conducted endured such events during Christmas 2001 and January 2003, facing dozens of deaths. It is necessary that other similar research projects be held in Family Health Units in other parts of the country so that there can be a more precise characterization of this demand.

\section{Conclusions}

Our study confirmed that there is a high prevalence of CMD in the population seen by the Family Health Units Staff in the Municipality of Petrópolis. Among these, we have to highlight anxiety and depressive ones, with a special mention to the high frequency of posttraumatic stress disorder, never mentioned by other studies previously held in Brazil. Comorbidity is high, having been found in $56 \%$ of the patients that came for the profiling. The clinical syndromes associated with the somatization phenomenon are also important, especially somatoform pain disorder and dissociative disorders. These data bring forth the importance of somatization in the demand of mental health in primary care in Brazil.

The great demand for treatment that mental health patients have been placing in the FHP Units imposes the inclusion of the family health teams in the assistance network on mental health. They should receive specific qualification for this kind of work, including training on how to diagnose and treat patients with anxiety, depressive and somatoform disorders.

\section{Acknowledgments}

We are thankful to the Petrópolis School of Medicine, through its Research Coordination, and the Health Foundation of Petrópolis for the operational support received. We also are very grateful for the FHP teams for all their help and dedication to this project.

\section{References}

1. Shapiro S, Skinner EA, Kessler LG, Von Korff M, German PS, Tischler GL, Leaf PJ, Benham L, Cottler L, Regier DA. Utilization of health and mental health services. Three Epidemiologic Catchment Area sites. Arch Gen Psychiatry. 1984;41(10):971-8.

2. Simon GE, VonKorff M. Somatization and psychiatric disorder in the NIMH Epidemiologic Catchment Area study. Am J Psychiatry. 1991;148(11):1494-500.

3. Ustun TB. Sartorius N. Mental IIIness in General Health Care: an International Study. Chichesser, England: John Wiley \& Sons; 1995.

4. Villano LA. Nanhay ALG, Moraes LR, Costa e Silva JA. Results from the Rio de Janeiro center. In: N ÜTBS, editor. Mental IIIness in General Health Care: an International Study. Chichesser, England: John Wiley \& Sons; 1995.

5. Villano LA. Problemas psicológicos e morbidade psiquiátrica em serviços de saúde não-psiquiátricos: o ambulatório de clínica geral [Tese de Doutorado]. São Paulo - UNIFESP; 1998.

6. Bridges KW., Goldberg DP. Somatic presentation of DSM III psychiatric disorders in primary care. J Psychosom Res. 1985;29(6):563-9.

7. Goldberg D, Huxley P. Common mental disorders: a bio-social model. London: Tavistock/ Routledge; 1992.

8. Goldberg DP, Bridges K. Somatic presentation of psychiatric illness in primary care setting. J Psychosom Res. 1988;32(2):137-44.

9. Jenkins R, Lewis G, Bebbington P, Brugha T, Farrell M, Gill B, Meltzer $\mathrm{H}$. The National Psychiatric Morbidity surveys of Great Britain-initial findings from the household survey. Psychol Med. 1997;27(4):775-89.

10. Weich S, Lewis G, Jenkins SP. Income inequality and the prevalence of common mental disorders in Britain. Br J Psychiatry. 2001;178:222-7

11. ArayaR, Fritsch R, Acuna J, Lewis G. Common mental disorders in Santiago, Chile: prevalence and socio-demographic correlates. $\mathrm{Br} \mathrm{J}$ Psychiatry. 2001;178:228-33.

12. Almeida-Filho N, Mari J de J, Coutinho E, França JF, Fernandes J, Andreoli SB, Busnello ED. Brazilian Multicenter Study of Psychiatric Morbidity. Methodological features and prevalence estimates. $\mathrm{Br} \mathrm{J}$ Psychiatry. 1997;171:524-9.

13. Araujo TM, Pinho OS, Almeida MM. Prevalence of psychological disorders among women according to socio demographic and housework characteristics. Rev Bras Saude Mater Infant. 2005;5(3) - eletronic version

14. Lima MC. Transtornos Mentais Comuns e Uso de Álcool na População Urbana de Botucatu: um Estudo de Comorbidade e Utilização de Serviços. [Tese]. São Paulo: USP; 2003.

15. Ludemir AB, Melo Filho DA. Condições de Vida e Estrutura Ocupacional Associados a Transtornos Mentais Comuns. Saude Publica. 2002;36(2). 
16. Maragno L, Goldbaum M, Gianini RJ, Novaes HM, Cesar EG Prevalência dos Transtornos Mentais Comuns em População Atendida pelo Programa de Saúde da Família (Qualis) no Município de São Paulo, Brasil. Cad Saude Publica. 2006;22(8):1639-48.

17. Lobo A, Garcia-Campayo J, Campos R, Campos R, Marcos G, Perez-Echeverria MJ. Somatisation in primary care in Spain I. Estimates of prevalence and clinical characteristics. Br J Psychiatry. 1996;168(3):344-8.

18. Weich S, Lewis G, Donmall R, Mann A. Somatic presentation of psychiatric morbidity in general practice. $\mathrm{Br} J$ Gen Pract. 1995;45(392): 143-7.

19. MaGPle Research Group. Psychological problems in New Zealand primary health care: a report on the pilot phase of the mental health and general practice investigation (MaGPle). N Z Med J. 2001;114(1124):13-6.

20. Kessler D, Bennewith O, Lewis G, Sharp D. Detection of depression and anxiety in primary care: follow-up study. BMJ. 2002;325(7371):1016-7.

21. Busnello ED, Lima B, Gomes R. Bertollote JM. Identificação e Manejo dos Doentes Mentais num Local de Cuidados Primários em Porto Alegre, Brasil. JBP. 1983;32(6):359-363

22. Mari JJ. Minor psychiatric morbidity in three primary care clinics in the city of São Paulo. Issues on the mental health of the urban poor. Soc Psychiatry Psychiatr Epidemiol. 1987;22:129-38.

23. Iacoponi E. The Detection of Emotional Disorders by Primary Care Physicians- a Study in São Paulo, Brazil. [PH.D. thesis]. Londres: University of London; 1989.

24. Campos Rodenas R. Estudio de la Morbilidad Psiquiátrica em el Area de Atencion Primaria de la Ciudad de Zaragoza. [Tese de Doutorado]. Zaragoza: Faculdad de Medicina de Zaragoza; 1993.

25. Janca A. TG, Isaac M. WHO International Study of Somatoform Disorders: an Overview of Methods and Preliminary Results. In: Somatoform disorders: a worldwide perspective. Tokyo: Springer; 1999.

26. Isaac M, Janca A, Burke KC, Costa e Silva JA, Acuda SW, Altamura AC, Burke JD, Chandrashekar CR, Miranda CT, Tacchini G. Medically unexplained somatic symptoms in different cultures. A preliminary report from phase I of the World Health Organization International Study of Somatoform Disorders. Psychother Psychosom. 1995;64(2):88-93.

27. CID-10. Classificação de Transtornos Mentais e de Comportamento da CID-10: Descrições Clínicas e Diretrizes Diagnósticas. Porto Alegre: Artes Médicas; 1993.

28. Goldberg DP, Blackwell B. Psychiatric illness in general practice. A detailed study using a new method of case identification. Br Med J. 1970;1(5707):439-43.

29. Mari JJ, Williams P. A comparison of the validity of two psychiatric screening questionnaires (GHQ-12 and SRQ-20) in Brazil using relative operating characteristic (ROC) analysis. Psychol Med. 1985;15(3):651-9.

30. Mari JJ, Williams P. Misclassification by Psychiatric Screening Questionnaires. Chron Dis. 1986;39(5):371-8.

31. Goldberg D, Williams P. A user's guide to the general health questionnaire. Windsor: NEFR Nelson; 1991.

32. Robins LN, Wing J, Wittchen HU, Helzer JE, Babor TF, Burke J, Farmer A, Jablenski A, Pickens R, Regier DA. The Composite International Diagnostic Interview. An epidemiological instrument suitable for use in conjuction with different diagnostic systems and in different cultures. Arch Gen Psychiatry. 1988;45(12):1069-77.

33. Quintana MI, Gastal FL, Jorge MR, Miranda CT, Andreoli SB. Validade e limitações da versão brasileira do Composite International Diagnostic Interview (CIDI 2.1). Rev Bras Psiquiatr. 2007;29(1):18-22.

34. CID-10. Diretrizes Diagnósticas e de Tratamento para Transtornos Mentais em Cuidados Primários/OMS. Porto Alegre: Artes Médicas; 1998.

35. Brugha TS. The end of the beginning: a requiem for the categorization of mental disorder? Psychological Medicine. 2002;32(7): 1149-54.

36. Kirmayer LJ, Robins J. Currents concepts of somatization: research and clinical perspective. Washington, DC: American Psichiatric Press; 1991.
37. Wise TN, Birket-Smith M. The somatoform disorders for DSM-V: the need for changes in process and content. Psychossomatics. 2002;43(6):437-40.

38. Garcia-Campayo J, Perez-Echeverria MJ, Campos R. Three forms of somatisation presenting in primary care settings in Spain. $\mathrm{Br} \mathrm{J}$ Psychiatry. 1998;186:554-60.

39. Mayou R, Kirmayer LJ, Simon G, Kroenke K, Sharpe M. Somatoform disorders: time for a new approach in DSM-V. Am J Psychiatry. 2005; 162(5):847-55.

40. Birket-Smith M, Mortensen EL. Pain in somatoform disorders: is somatoform pain disorder a valid diagnosis? Acta Psychiatr Scand. 2002; 106(2): 103-8 